\title{
PERFORMANCE OF SITE VELOCITY PREDICTION IN SUNDALAND
}

\author{
Amir Husni Kamaludin ${ }^{1 *}$, Wan Anom Wan Aris ${ }^{1}$, Tajul Ariffin Musa ${ }^{1}$, Abdullah Hisam Omar $^{1}$, Ahmad Zuri Sha'ameri ${ }^{2}$ \\ ${ }^{1}$ Geomatic Innovation Research Group, Faculty of Built Environment and Surveying, Universiti Teknologi Malaysia - \\ amirhusnikamaludin@gmail.com,wananom@utm.my, tajulariffin@utm.my, abdullahhisham@utm.my \\ ${ }^{2}$ School of Electrical Engineering, Faculty of Engineering, Universiti Teknologi Malaysia - ahmadzuri@utm.my
}

Commission 4, WG 7

KEY WORDS: Site Velocity, Plate Motion, Least Square Collocation, Crustal Deformation, Tectonic Geodesy

\begin{abstract}
Global Positioning System (GPS) technique has been extensively implemented in determination of crustal deformation globally. With the ability of providing solution up to milimeter $(\mathrm{mm})$ level, this technique has proven to provide a precise estimate of site velocity that represents the actual motion of tectonic plate over a period. Therefore, this study aims to evaluate the site velocity estimation from GPS-derived daily position of station, respective to the global plate motion model and predicted site velocity via Least-Squares Collocation (LSC) method within the tectonically active region of Sundaland. The findings have indicated that stations with precise velocity estimates were consistent with global plate model and predicted velocity, with velocity residuals of $5 \mathrm{~mm}-10 \mathrm{~mm}$. However, stations that were severely impacted by continuous earthquake events such as in Sumatra were believed to be induced by the impact with consistently large velocity residuals up to $37 \mathrm{~mm}$. Following the outcomes, this study has provided an insight on the post-seismic decay period plate motion which are induced by continuous tectonic activities respective to modelled plate motion.
\end{abstract}

\section{INTRODUCTION}

Global Positioning System (GPS) technique has frequently implemented in determination of geophysical events such as plate motion (Duman and Sanli, 2019). Observation from permanent GPS networks have proven to detect inter-plate and intra-plate deformation. Series of GPS observations combined with multiple geodetic techniques have also contributed to support the global plate motion model which are based on geophysical and geological data (Bastos et al., 2010) vice-versa whereby plate tectonic models can be biased by local effects and show inconsistencies while GPS observations depict motions over a short time interval, thus representing the present-day plate motion.

Therefore, this study intends to examine the efficiency of GPSderived velocity, respective to the predicted velocities via global plate motion models. Site velocity prediction by Least-Squares Collocation (LSC) was also included to examine the capability of the model in velocity prediction. Within the tectonically active region such as Sundaland, observed velocity from GPS could differ from the predicted velocity by model as it is biased by local effects. Thus, the findings will give an insight towards the present-day plate motion respective to the modelled plate motion.

\section{SEISMICITY OF THE SUNDALAND}

The Sundaland plate region was regarded as a stable region (Hall, 2014) before the occurrences of major earthquakes along the Sumatra Subduction Zone (SSZ) and became a tectonically active region to this day. Holt et al. (1995) model indicated that the Sundaland has an eastward velocity respective to Eurasia at increasing southward from $10 \mathrm{~mm} / \mathrm{y}$ to the north of South China to about 20 to $30 \mathrm{~mm} / \mathrm{y}$ to the south (Holt et al., 1995; ChamotRooke et al., 1999). On the other hand, Geodynamics of South and South-East Asia project (GEODYSSEA) GPS measurement showed that the Sundaland rotates clockwise around a pole of rotation located south of Australia, with an east to northeast velocity increasing from $14 \mathrm{~mm} / \mathrm{y}$ to the south to $23 \mathrm{~mm} / \mathrm{y}$ to the north (Chamot-Rooke, 1999).

Four (4) major earthquakes with magnitude of $>7.0 \mathrm{Mw}$ occurred on the western subduction zone of Sundaland from year 2004 until 2012 has resulted in a substantial impact towards the seismicity of the region of which it had disturbed the surrounding plate and triggered instability of the Sundaland. In a tectonically complicated region such as the Sundaland, series of earthquakes are thought to have increased lithosphere stress and raised seismic hazard over the region (Feng et al., 2015).

The 2004 Sumatra-Andaman earthquake that occurred on 26 December 2004 is considered as the largest earthquake that hits the region ever since. Erupting with a magnitude of $9.1 \mathrm{Mw}$, it had severely impacted the Sumatra region as well as the western coast of Peninsular Malaysia. Consecutively, two earthquakes in the following years; 2005 Nias-Simuelue and 2007 Bengkulu earthquakes occurred within the same subduction zone, believed to be triggered by the 2004 earthquake (Feng et al., 2015; Aris, 2018) while the 2012 Indian Ocean earthquake, relatively occurred due to the stress transfer of the 2004 and 2005 earthquake (Gunawan et al., 2016).

These earthquakes also caused several tremors to be felt in Peninsular Malaysia (Aris, 2018) whereby series of moderate seismic activities by the Malaysia Meteorological Department (MMD) occurring in recent years such as tremors Bukit Tinggi and Jerantut, and sink holes around Batu Gajah and Ipoh are believed to be originated from these earthquakes (Aris, 2018). It is suspected that these tremors are resulting from the reactivation of major faults due to the impact of major earthquakes over the years.

\section{METHODOLOGY}

In quantifying the observed velocity and predicted velocity within the GPS CORS network in Sundaland, this study has been 
phased into three stages. The first stage is determining the observed site velocity whereby GPS observation data will be processed using Bernese 5.2 high precision geodetic software in estimating GPS daily solution for selected MyRTKnet and SuGAr stations in Sumatra, Peninsular Malaysia and Northern Borneo area. Second stage is determining the predicted velocity through two (2) method; from plate motion model and LSC interpolation/extrapolation of velocity. Third stage will be the assessment on the performance of site velocity prediction, whereby the residuals between the observed and predicted velocity from the two methods will be analysed. Figure 1 shows the methodology implemented in this study.

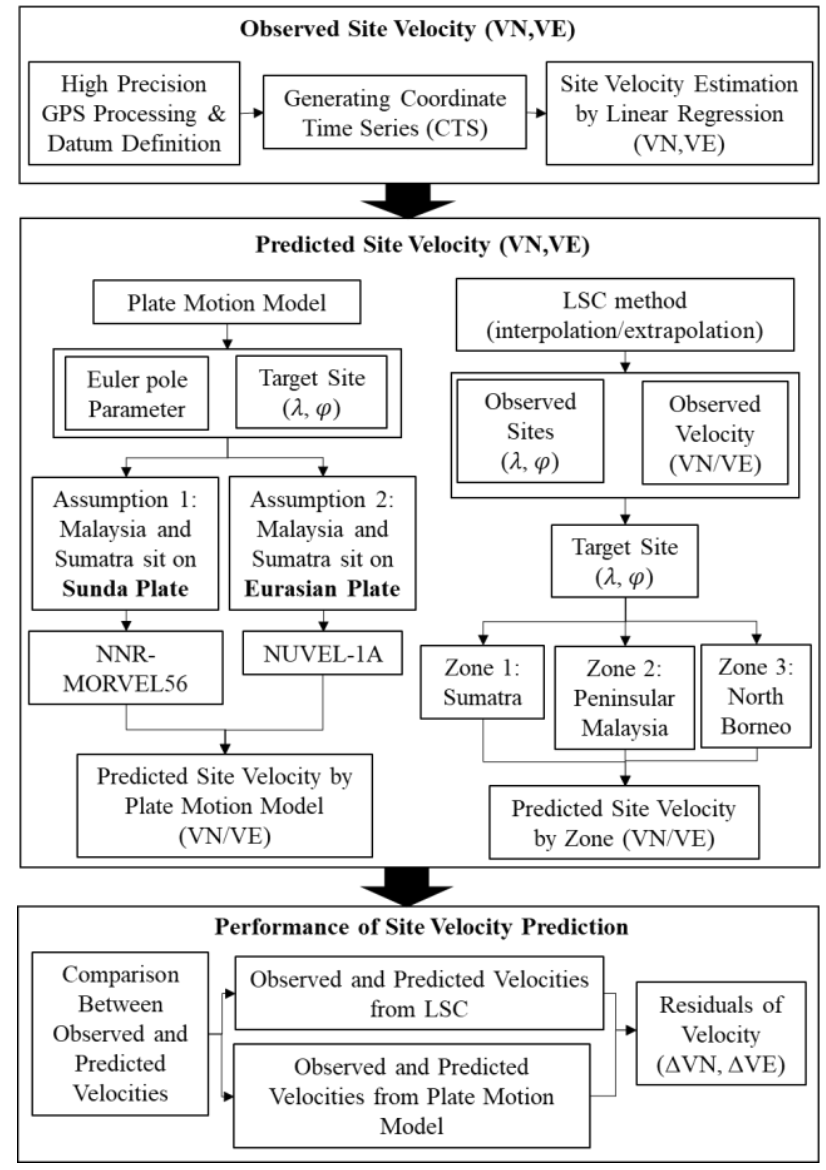

Figure 1. Methodology of the study.

\subsection{GPS-Derived Site Velocity}

Daily GPS solutions of year 2014 were constrained to International Terrestrial Reference Frame 2008 (ITRF2008) datum for selected MyRTKnet sites within Peninsular Malaysia and North Borneo region along with SuGAr sites within the region of Sumatra. From the processed daily GPS solutions, time series of the selected sites were plotted and fitted by linear regression model, following functional model shown in Equation 1.

$$
y=a t+b
$$

where $a$ and $b$ are the coefficients to be estimated; velocity and initial position and $t$ is the corresponding epochs. Following this equation, velocity of the site in Northing and Easting components were determined.

\subsection{Predicted Site Velocity}

This study implements two approach of site velocity prediction; via plate motion model and Least-Squares Collocation method. Predicting velocity from plate motion model requires the knowledge of the location of site in 3D Cartesian coordinates or geographical coordinates along with its Euler Pole parameters. Goudarzi et al., (2014) summarizes the Euler theorem for defining the velocity prediction, as follows:

$$
\mathbf{v}_{i}^{p}=\boldsymbol{\Omega}^{p} \times \mathbf{x}_{i}=\left[\begin{array}{ccc}
0 & -\omega_{z} & \omega_{y} \\
\omega_{z} & 0 & -\omega_{x} \\
-\omega_{y} & \omega_{x} & 0
\end{array}\right]^{p}\left[\begin{array}{l}
x \\
y \\
z
\end{array}\right]_{i}
$$

Whereby $\mathbf{v}_{i}^{p}$ and $\mathbf{x}_{i}\left(x_{i}, y_{i}, z_{i}\right)^{T}$ represent the velocity and the position of the station $i$, and $\Omega^{p}\left(\omega_{x}^{p}, \omega_{y}^{p}, \omega_{z}^{p}\right)$ represent the angular velocity or the Euler vector of the plate $p$ associated with the station $i$. Following the Euler theorem, the site velocity were also predicted from two global plate motion model, namely the NNR-MORVEL56 (Argus et al., 2011) and NUVEL-1A (DeMets et al., 1994) by utilizing the UNAVCO Plate Motion Calculator.

Following the observed and predicted velocities from the two plate motion model, an approach of velocity prediction by LSC (Moritz, 1980) were also applied, with the knowledge of at least three (3) observed sites and one (1) predicted site. Equation 3 shows the functional model implemented.

$$
S=C_{S T} C_{L}^{-1} L
$$

Whereby $S$ is the predicted velocity. $C_{S T}$ is empirical covariance functional matrix between signal $T$ (i.e., intra-plate site velocity) at the observation points while $C_{L}$ is the total covariance matrix of observation.

\section{RESULTS AND ANALYSIS}

Several analyses were done towards the GPS-derived site velocity as well as the predicted velocity in understanding the depiction of the Sundaland motion. Thus, this section comprises of four parts: (1) GPS-derived site velocities of MyRTKnet and SuGAr sites, (2) Predicted velocities from plate motion model; NNR-MORVEL56 and NUVEL-1A. (3) Predicted velocities by Least-Squares Collocation method and (4) Analysis on the performance of the site velocity prediction.

\subsection{GPS-Derived Site Velocities of MyRTKnet and SuGAr Sites}

GPS Coordinate Time Series (CTS) for the selected MyRTKnet and SuGAr sites were plotted and velocity for each of the sites were estimated by applying Equation 1 into the time series. Figure 2 shows the time series plotted for MyRTKnet sites; ARAU in Peninsular Malaysia and MTAW in North Borneo while Figure 3 shows the time series plotted SuGAr sites; ABGS and MNNA in the Sumatra region. Estimated velocities for these sites are shown in Table 1. 


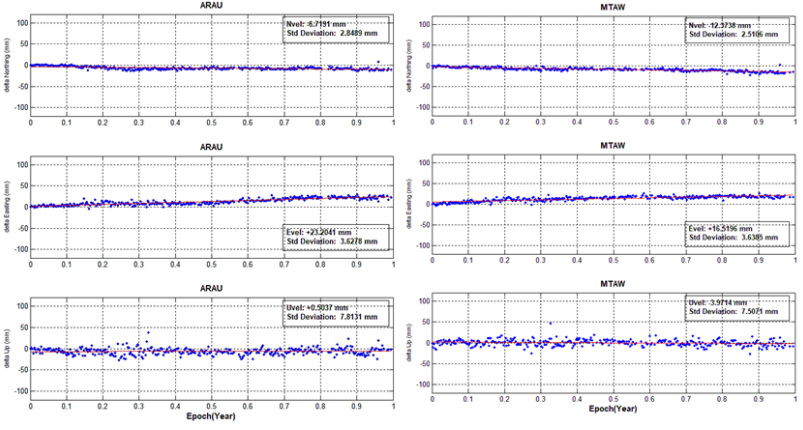

Figure 2. GPS CTS of MyRTKnet sites; ARAU and MTAW.

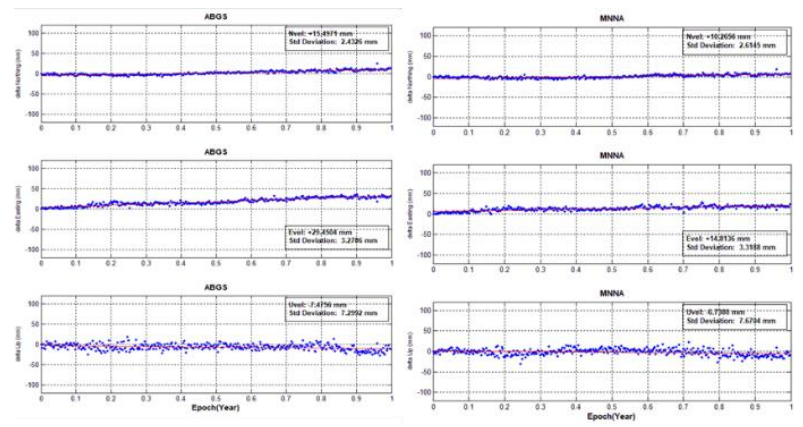

Figure 3. GPS CTS of MyRTKnet sites; ARAU and MTAW.

\begin{tabular}{|l|c|c|}
\hline \multirow{2}{*}{ STATION } & \multicolumn{2}{|c|}{ Observed Velocity } \\
\cline { 2 - 3 } & VN $(\mathbf{m m})$ & VE $(\mathbf{m m})$ \\
\hline AMAN & -16.382 & 31.094 \\
\hline ARAU & -6.719 & 23.204 \\
\hline BANT & -2.615 & 28.082 \\
\hline BELA & -3.998 & 25.245 \\
\hline GETI & -5.334 & 27.077 \\
\hline GMUS & -5.856 & 24.001 \\
\hline KUDA & -10.303 & 21.910 \\
\hline MIRI & -7.917 & 23.092 \\
\hline MTAW & -12.374 & 16.520 \\
\hline MUKA & -6.765 & 23.157 \\
\hline PEKN & -5.663 & 26.915 \\
\hline RANA & -10.162 & 28.728 \\
\hline TGPG & -4.518 & 26.028 \\
\hline TLOH & -5.109 & 28.324 \\
\hline ABGS & 15.497 & 29.450 \\
\hline MNNA & 10.266 & 14.814 \\
\hline PRKB & 28.350 & 13.601 \\
\hline TRTK & 11.647 & 25.450 \\
\hline
\end{tabular}

Table 1. Observed velocities at MyRTKnet and SuGAR sites.

Referring to Figure 2 and Table 1, MyRTKnet sites in shows and south-eastward trend of motion, dominantly towards east at an average velocity of $24 \mathrm{~mm} / \mathrm{year}$ while SuGAr sites trends northeastward motion at $21 \mathrm{~mm} /$ year (refer Figure 2 and Table 1). It can be observed that both of the sites are trending in linear motion within the post-seismic decay period after the last major earthquake that occurred in 2012. Figure 4 shows the representation of observed velocity vector for both MyRTKnet and SuGAr sites.

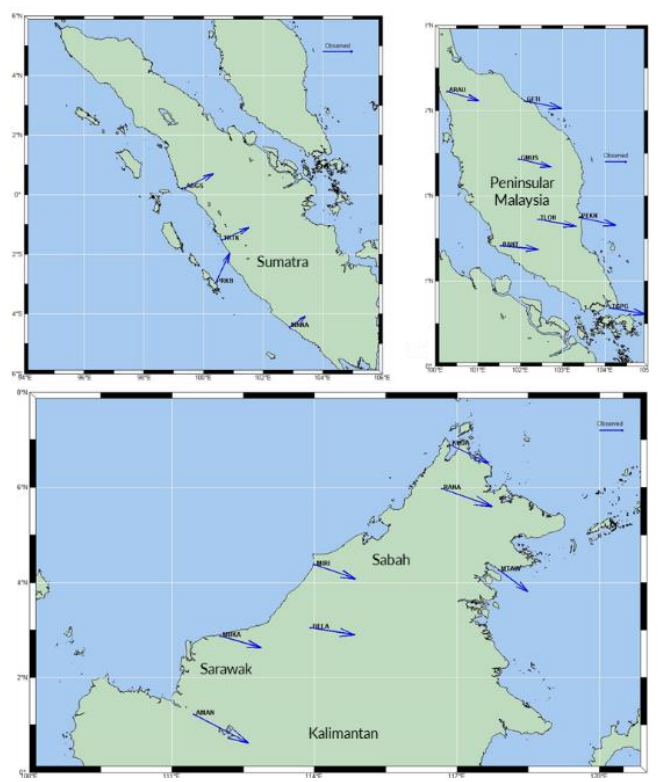

Figure 4. Observed velocity vector plot of MyRTKnet and SuGAr sites.

\subsection{Predicted Velocities from Plate Motion Model; NNR- MORVEL56 and NUVEL-1A}

Following the determination of GPS-derived observed site velocities, velocity prediction was performed with the knowledge of the site locations along with its Euler pole parameters. Table 2 shows the predicted site velocity, deducted from two plate motion model; NNR-MORVEL56 and NUVEL-1A following the assumptions as shown in Figure 1.

\begin{tabular}{|l|c|c|c|c|}
\hline \multirow{2}{*}{ STATION } & \multicolumn{2}{|c|}{ NNR-MORVEL56 } & \multicolumn{2}{c|}{ NUVEL-1A } \\
\cline { 2 - 5 } & $\begin{array}{c}\text { VN } \\
(\mathrm{mm})\end{array}$ & $\begin{array}{c}\text { VE } \\
(\mathrm{mm})\end{array}$ & $\begin{array}{c}\text { VN } \\
(\mathrm{mm})\end{array}$ & $\begin{array}{c}\text { VE } \\
(\mathrm{mm})\end{array}$ \\
\hline AMAN & -10.050 & 18.960 & -11.410 & 20.360 \\
\hline ARAU & -7.360 & 20.200 & -8.880 & 21.540 \\
\hline BANT & -7.680 & 19.380 & -9.190 & 20.760 \\
\hline BELA & -10.590 & 19.320 & -11.910 & 20.690 \\
\hline GETI & -7.820 & 20.130 & -9.320 & 21.460 \\
\hline GMUS & -7.790 & 19.840 & -9.290 & 21.190 \\
\hline KUDA & -11.210 & 19.980 & -12.480 & 21.250 \\
\hline MIRI & -10.610 & 19.580 & -11.930 & 20.920 \\
\hline MTAW & -11.430 & 19.500 & -12.670 & 20.840 \\
\hline MUKA & -10.170 & 19.310 & -11.530 & 20.670 \\
\hline PEKN & -8.140 & 19.510 & -9.620 & 20.880 \\
\hline RANA & -11.180 & 19.830 & -12.450 & 21.120 \\
\hline TGPG & -8.320 & 19.020 & -9.790 & 20.420 \\
\hline TLOH & -7.900 & 19.510 & -9.400 & 20.890 \\
\hline ABGS & -7.130 & 18.750 & -8.670 & 20.160 \\
\hline MNNA & -8.020 & 17.540 & -9.510 & 19.010 \\
\hline PRKB & -7.390 & 17.920 & -8.910 & 19.370 \\
\hline TRTK & -7.450 & 18.300 & -8.970 & 19.740 \\
\hline
\end{tabular}

Table 2. NNR-MORVEL56 and NUVEL-1A predicted velocity 
Referring to Table 2, predicted velocities between NNRMORVEL56 and NUVEL-1A for MyRTKnet and SuGAr sites shows a trend of south-eastward motion at an average of 20 $\mathrm{mm}$ /year. Slight difference of velocity estimates between the two plate motions model were believed due to different definition of Euler pole parameters between the model. Figure 5 shows the predicted velocity vector plot for NNR-MORVEL56 with respect to the GPS-derived observed velocity while Figure 6 shows the predicted velocity vector plot for NUVEL-1A model, respective to the GPS-derived observed velocity.

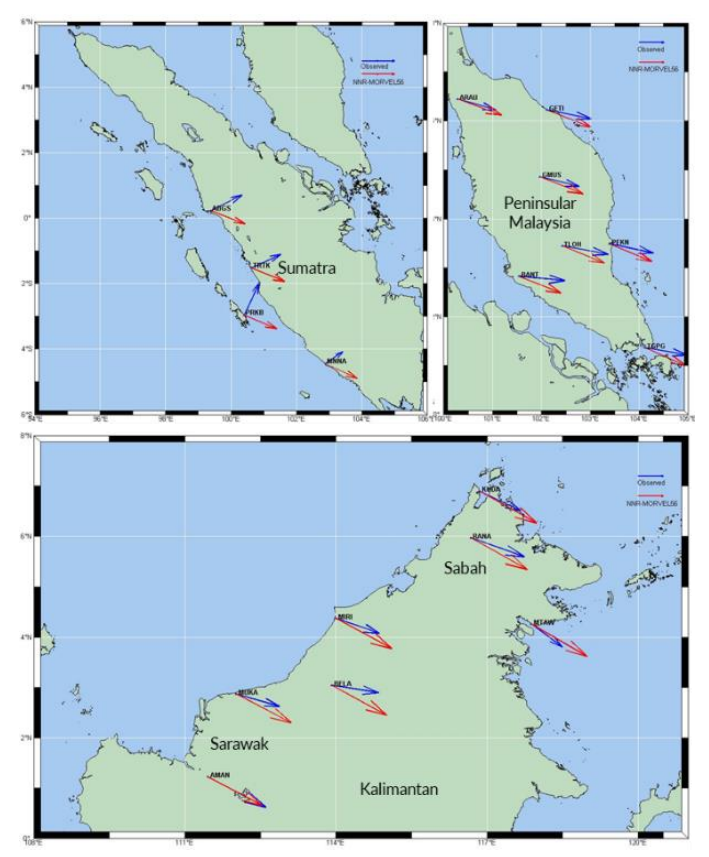

Figure 5. Predicted NNR-MORVEL56 velocity with observed velocity vector plot of MyRTKnet and SuGAr sites.

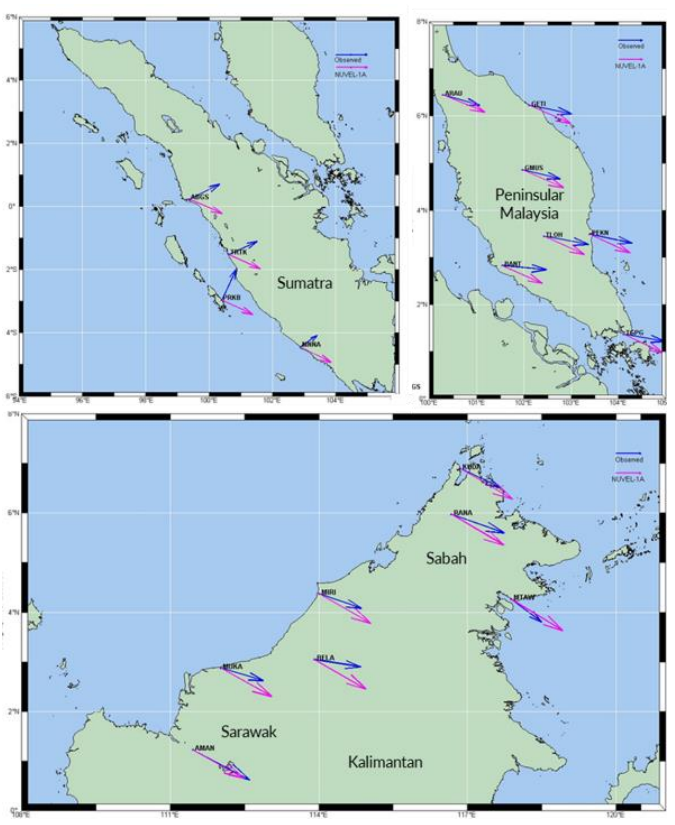

Figure 6. Predicted NUVEL-1A velocity with observed velocity vector plot of MyRTKnet and SuGAr sites.

\subsection{Predicted Velocities by Least-Squares Collocation Method}

Following the prediction of velocity from the two plate motion model; NNR-MORVEL56 and NUVEL-1A, an approach of velocity prediction by implementing Least-Squares Collocation (LSC) method was performed to examine the capability of this model for velocity prediction. Referring to Figure 1, the velocity prediction by LSC approach was performed according to three zones; Sumatra, Peninsular Malaysia and North Borneo. Within each of these zones, several sites were treated as target sites whereby the velocity of these sites will be predicted with the knowledge of three (3) neighbouring sites. Table 3 shows the predicted velocities of the selected target sites by implementing LSC. Discussion on the LSC-predicted velocity will be in the next section.

\begin{tabular}{|l|c|c|}
\hline \multirow{2}{*}{ STATION } & \multicolumn{2}{|c|}{ Predicted LSC Velocity } \\
\cline { 2 - 3 } & VN $(\mathbf{m m})$ & VE $(\mathbf{m m})$ \\
\hline TLOH & -4.719 & 27.763 \\
\hline RANA & -11.367 & 31.383 \\
\hline TRTK & 24.798 & 14.222 \\
\hline PEKN & -1.913 & 13.871 \\
\hline BANT & -3.259 & 15.202 \\
\hline ARAU & 3.401 & 30.413 \\
\hline BELA & -3.919 & 10.545 \\
\hline
\end{tabular}

Table 3. LSC- predicted velocity for MyRTKnet sites and SuGAr sites.

\subsection{Analysis on Performance of Site Velocity Prediction}

GPS-derived site velocity followed by predicted velocity from the plate motion model and LSC method were analysed through residuals between observed velocity and predicted velocity from the two different models, defined by the residuals of the velocity that has been determined. Table 4 shows the residuals between GPS-derived observed velocities and predicted velocities from NNR-MORVEL56 and NUVEL-1A plate motion model

\begin{tabular}{|l|c|c|c|c|}
\hline \multirow{2}{*}{ STATION } & \multicolumn{2}{|c|}{$\begin{array}{c}\text { Residuals } \\
\text { (Observed } \\
\text { Velocity vs NNR- } \\
\text { MORVEL56) }\end{array}$} & \multicolumn{2}{c|}{$\begin{array}{c}\text { Residuals } \\
\text { Observed Velocity } \\
\text { vs NUVEL-1A) }\end{array}$} \\
\cline { 2 - 5 } & $\begin{array}{c}\text { VN } \\
(\mathbf{m m})\end{array}$ & $\begin{array}{c}\text { VE } \\
(\mathbf{m m})\end{array}$ & $\begin{array}{c}\text { VN } \\
(\mathbf{m m})\end{array}$ & $\begin{array}{c}\text { VE } \\
(\mathbf{m m})\end{array}$ \\
\hline AMAN & -6.332 & 12.134 & -4.972 & 10.734 \\
\hline ARAU & 0.641 & 3.004 & 2.161 & 1.664 \\
\hline BANT & 5.065 & 8.702 & 6.575 & 7.322 \\
\hline BELA & 6.592 & 5.925 & 7.912 & 4.555 \\
\hline GETI & 2.486 & 6.947 & 3.986 & 5.617 \\
\hline GMUS & 1.934 & 4.161 & 3.434 & 2.811 \\
\hline KUDA & 0.907 & 1.930 & 2.177 & 0.660 \\
\hline MIRI & 2.693 & 3.512 & 4.013 & 2.172 \\
\hline MTAW & -0.944 & -2.980 & 0.296 & -4.320 \\
\hline MUKA & 3.405 & 3.847 & 4.765 & 2.487 \\
\hline PEKN & 2.477 & 7.405 & 3.957 & 6.035 \\
\hline RANA & 1.018 & 8.898 & 2.288 & 7.608 \\
\hline TGPG & 3.802 & 7.008 & 5.272 & 5.608 \\
\hline TLOH & 2.791 & 8.814 & 4.291 & 7.434 \\
\hline ABGS & 22.627 & 10.700 & 24.167 & 9.290 \\
\hline MNNA & 18.286 & -2.726 & 19.776 & -4.196 \\
\hline
\end{tabular}




\begin{tabular}{|l|l|l|l|l|}
\hline PRKB & 35.740 & -4.319 & 37.260 & -5.769 \\
\hline TRTK & -6.653 & 32.900 & -8.093 & 34.420 \\
\hline
\end{tabular}

Table 4. Residuals between GPS-derived velocities and predicted velocities from NNR-MORVEL56 and NUVEL-1A plate motion model.

Referring to Table 4, The residuals between the observed and predicted velocity from both NNR-MORVEL56 (Figure 7) and NUVEL-1A (Figure 8) for MyRTKnet sites shown a relatively small residuals averaging at 5-10 $\mathrm{mm}$, while SuGAr sites shown significantly large residuals, up to $37 \mathrm{~mm}$. It is suspected that SuGAr sites within the Sumatra region are largely influenced by local effect; continuous impact of earthquakes within the Sumatra Subduction Zone. Despite showing small residuals between observed and predicted velocities from the plate motion model, both MyRTKnet sites and SuGAr sites were still induced by the effects of the major earthquakes within the post-seismic decay period.

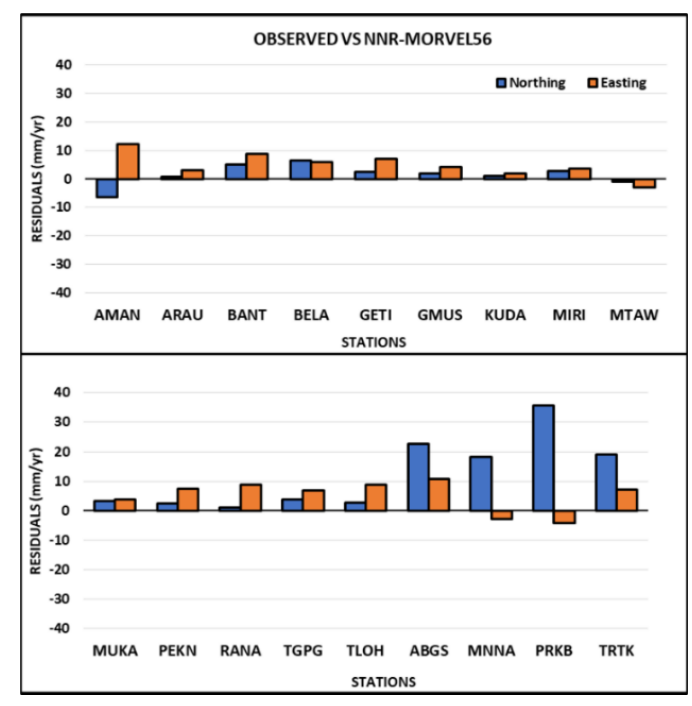

Figure 7. Residual plot between GPS-derived velocities and NNR-MORVEL56 plate motion model.

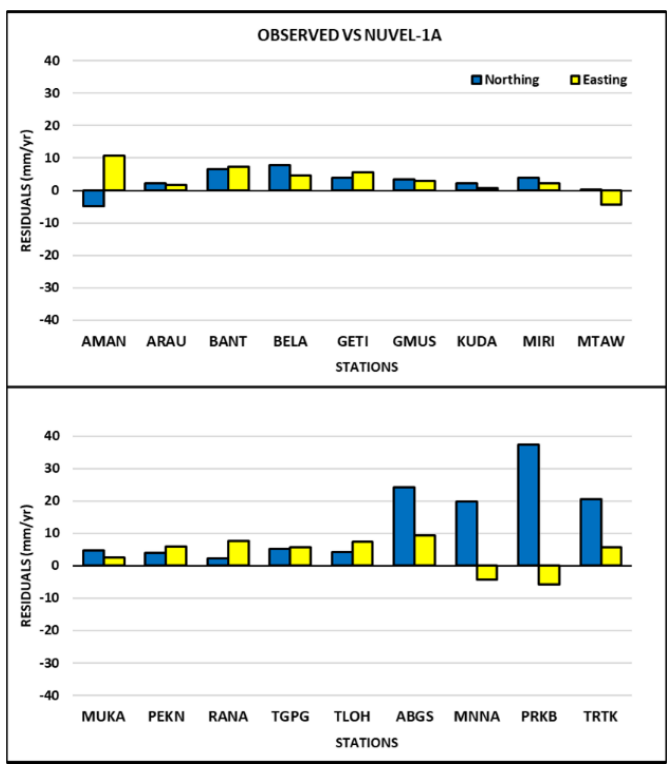

Figure 8. Residual plot between GPS-derived velocities and NUVEL-1A plate motion model.
Following the residuals between the observed and predicted from the plate motion model, the residuals between GPS-derived velocity and predicted velocity by LSC approach for selected MyRTKnet and SuGAr sites was also determined. Table 5 shows residuals between GPS-derived observed velocities and predicted velocities via LSC Figure 9 shows the residual plot between the GPS-derived velocity and predicted velocity via LSC approach.

\begin{tabular}{|l|c|c|}
\hline \multirow{2}{*}{ STATION } & \multicolumn{2}{|c|}{$\begin{array}{c}\text { Residuals (Observed Velocity VS LSC- } \\
\text { Predicted) }\end{array}$} \\
\cline { 2 - 3 } & VN (mm) & VE $(\mathbf{m m})$ \\
\hline TLOH & -0.389 & 0.561 \\
\hline RANA & 1.204 & -2.655 \\
\hline TRTK & -13.151 & 11.228 \\
\hline PEKN & -3.750 & 13.044 \\
\hline BANT & 0.644 & 12.879 \\
\hline ARAU & -10.120 & -7.209 \\
\hline BELA & -0.079 & 14.700 \\
\hline
\end{tabular}

Table 5. Residuals between GPS-derived velocities and predicted velocities via LSC.

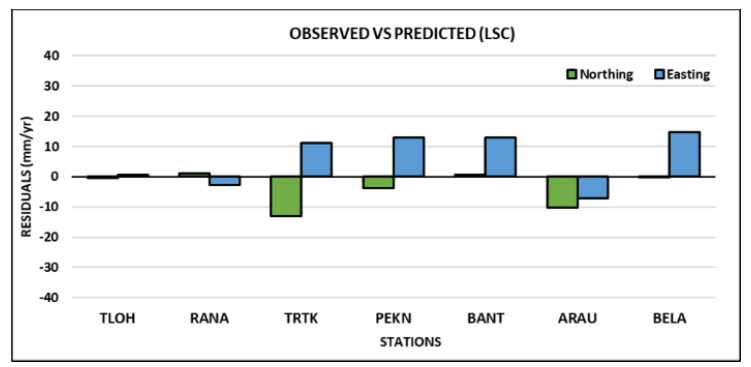

Figure 7. Residual plot between GPS-derived velocities and LSC-predicted velocities

On the contrary, predicted velocities of the residuals between the predicted site velocities by LSC at known points in Peninsular Malaysia, North Borneo and Sumatra are relatively small averaging between $0.5 \mathrm{~mm}$ up to $15 \mathrm{~mm}$. Referring to Table 9 , MyRTKnet sites; TLOH and RANA shown a small residual between 0.5-2.6 mm while SuGAr sites shows average residual of $12 \mathrm{~mm}$, lower compared to predicted velocity from the plate motion model. Small residuals between the GPS-derived velocity and the LSC-predicted velocity have shown efficiency of the model to be implemented for velocity prediction.

\section{CONCLUSION}

The observed velocity of MyRTKnet shows a trend of northeastward motion at an average of $24 \mathrm{~mm} /$ year while both NNRMORVEL56 and NUVEL-1A velocity prediction shows that the sites are trending south-east motion at an average of $20 \mathrm{~mm} /$ year. Slight difference of velocity estimates between the two plate motions model were believed due to different definition of Euler pole parameters between the model.

The residuals between the observed and predicted velocity from both NNR-MORVEL56 and NUVEL-1A for MyRTKnet sites are relatively small, averaging at $5-10 \mathrm{~mm}$ while SuGAr sites shown large residuals, up to $37 \mathrm{~mm}$, indicating the local effect bias in the observation Meanwhile, residuals between the predicted site velocities by LSC at selected sites in Peninsular Malaysia, North Borneo and Sumatra are relatively small averaging between $0.5 \mathrm{~mm}$ up to $15 \mathrm{~mm}$, thus indicating that the model is efficient in predicting velocities. 
However, velocity prediction by LSC can be optimized with larger number of observed sites along with enhanced geometry through grid network development between the observed sites and predicted sites.

\section{ACKNOWLEDGEMENT}

The authors would like to thank the Ministry of Higher Education (MOHE) Malaysia for providing the funds through the Fundamental Research Grant FRGS/1/2019/TK04/UTM/02/4 (Vot R.J130000.7851.5F209) which has contributed to the vital findings of this study.

\section{REFERENCES}

Argus, D. F., Gordon, R. G., \& DeMets, C. 2011. Geologically current motion of 56 plates relative to the no-net-rotation reference frame. Geochemistry, Geophysics, Geosystems, 12(11), n/a. doi.org/10.1029/2011gc003751

Aris, W. A. W., 2018. Spatio-Temporal Crustal Deformation Model of Sundaland in Malaysia Using Global Positioning System (PhD Thesis ed.). Universiti Teknologi Malaysia

Bastos, L., Bos, M., \& Fernandes, R. M. 2010. Deformation and Tectonics: Contribution of GPS Measurements to Plate Tectonics - Overview and Recent Developments. Sciences of Geodesy - I, 155-184. doi.org/10.1007/978-3-642-11741-1

Chamot-Rooke, N., \& le Pichon, X. 1999. GPS determined eastward Sundaland motion with respect to Eurasia confirmed by earthquakes slip vectors at Sunda and Philippine trenches. Earth and Planetary Science Letters, 173(4), 439-455. doi.org/10.1016/s0012-821x(99)00239-3

DeMets, C., Gordon, R. G., Argus, D. F., \& Stein, S. 1994. Effect of recent revisions to the geomagnetic reversal time scale on estimates of current plate motions. Geophysical Research Letters, 21(20), 2191-2194. doi.org/10.1029/94g10211

Duman, H., \& Sanli, D. U. 2019. Assessment of geodetic velocities using GPS campaign measurements over long baseline lengths. Natural Hazards and Earth System Sciences, 19(3), 571582. doi.org/10.5194/nhess-19-571-2019

Feng, L., Hill, E. M., Banerjee, P., Hermawan, I., Tsang, L. L. H., Natawidjaja, D. H., Suwargadi, B. W., \& Sieh, K. 2015. A unified GPS-based earthquake catalog for the Sumatran plate boundary between 2002 and 2013. Journal of Geophysical Research: $\quad$ Solid Earth, 120(5), 3566-3598. doi.org/10.1002/2014jb011661

Goudarzi, M. A., Cocard, M., \& Santerre, R. 2013. EPC: Matlab software to estimate Euler pole parameters. GPS Solutions, 18(1), 153-162. doi.org/10.1007/s10291-013-0354-4

Gunawan, E., Maulida, P., Meilano, I., Irsyam, M., \& Efendi, J. 2016. Analysis of Coseismic Fault Slip Models of the 2012 Indian Ocean Earthquake: Importance of GPS Data for Crustal Deformation Studies. Acta Geophysica, 64(6), 2136-2150. doi.org/10.1515/acgeo-2016-0106

Hall, R. 2014. The Origin of Sundaland. Proceedings of Sundaland Resources 2014 MGEI Annual Convention.

Holt, W. E., Li, M., \& Haines, A. J. 1995. Earthquake strain rates and instantaneous relative motions within central and eastern
Asia. Geophysical Journal International, 122(2), 569-593. doi.org/10.1111/j.1365-246x.1995.tb07014.x

Moritz, H. 1980. Advanced physical geodesy. Advances in Planetary Geology.

Jagoda, M., \& Rutkowska, M. 2020. An Analysis of the Eurasian Tectonic Plate Motion Parameters Based on GNSS Stations Positions in ITRF2014. Sensors, 20(21), 6065. doi.org/10.3390/s20216065 